\title{
Risk Factors of Deterioration in Quality of Life Scores in Thyroid Cancer Patients After Thyroidectomy
}

This article was published in the following Dove Press journal: Cancer Management and Research

\author{
Jie $\mathrm{Li}(\mathbb{D}$ \\ Ling Bo Xue \\ Xiao Yi Gong \\ Yan Fang Yang \\ Bu Yong Zhang \\ Jian Jin \\ Qing Feng Shi \\ Yong Hong Liu (1D
}

Thyroid and Breast Surgery, Cangzhou Central Hospital, Cangzhou City 061000, People's Republic of China
Correspondence: Yong Hong Liu Thyroid and Breast Surgery, Cangzhou Central Hospital, No. 16 Xinhua Road, Yunhe Qu, Cangzhou City 061000,

People's Republic of China

Tel +86- I5733758 II0

Fax +86 317-207-2692

Email lyh15733758II0@hotmail.com
Objective: Despite the expectation of normal life expectancy for thyroid cancer, there are concerns about the decreased quality of life $(\mathrm{QoL})$. The present study investigated the potential risk factors of deterioration in QoL scores in thyroid cancer patients after thyroidectomy.

Materials and methods: A total of 286 patients who were diagnosed with thyroid cancer after thyroidectomy were involved in this prospective, single-center, observational study from November 2018 to June 2019. The European Organization for Research and Treatment of Cancer Quality of Life Questionnaire Core 30 was used to assess the QoL 3 months after thyroidectomy. We investigated the effects of demographics (age, gender, education, marital status, area of residence, and annual mean income), tumor characteristics (histology, clinical stage, presence of metastasis, surgery type, and radiotherapy), and neurological deficits induced by recurrent nerve or superior laryngeal injury on QoL.

Results: The mean overall QoL in thyroid cancer survivors was $65.93 \pm 9.00$ (on a scale of $0-100$, where 100 was the best). Multivariate regression analysis confirmed that clinical stage $(P<0.010)$, surgery type $(P<0.001)$, histology $(P<0.001)$, neurological deficits $(P<$ $0.001)$, and marital status $(P<0.001)$ were independent risk factors for decreased QoL 3 months after thyroidectomy.

Conclusion: Our study indicated that clinical stage, surgery type, histology, neurological deficits, and marital status were independent risk factors for decreased QoL at 3 months after thyroidectomy. Further exploration and validation of these findings in larger prospective studies are warranted.

Keywords: quality of life, thyroid cancer, thyroidectomy

\section{Introduction}

The incidence of thyroid cancer has been increasing in China and in several parts of the world, and this increase is predominant among differentiated thyroid cancers, which are characterized by good outcomes. The average life expectancy of thyroid cancer patients is similar to that of the general population. ${ }^{1,2}$ Quality of life (QoL) is a subjective clinical endpoint that has become increasingly important in health outcomes research, particularly in cancer clinical trials, over the past two decades. ${ }^{3}$ Therefore, the current thyroid cancer guidelines for patient care are shifting toward the decrease in morbidity and increase in QoL from merely increasing the survival rate. ${ }^{4}$

Previous studies reported that thyroid cancer survivors have impairments in health-related QoL. ${ }^{5-8}$ More surprisingly, the QoL in thyroid cancer patients is at 
the same level as that in patients with more aggressive cancers. ${ }^{9}$ The assessment and identification of risk factors of decreased QoL in thyroid cancer survivors provide insights into their experiences of the disease and might support the choice and design of appropriate interventions and survivorship care plans. Thus, in this prospective, single-center, observational study, we investigated the potential risk factors of QoL deterioration in thyroid cancer patients undergoing thyroidectomy.

\section{Materials and Methods}

This study was conducted in accordance with Helsinki declaration and approved by the ethics committee of Cangzhou Central Hospital (No. 2017-081-01). All eligible participants were familiarized in advance with the study, its objectives and methods, the confidentiality of data, and the possibility of withdrawing from the study at any time. These participants also provided a written consent to participate in the study.

\section{Study Population}

After receiving Institutional Review and Ethics Board approval, patients that were recently diagnosed with thyroid cancer and underwent thyroidectomy were involved in this prospective, single-center, observational study from November 2018 to June 2019. The inclusion criteria were as follows: age $\geq 18$ years at diagnosis; primary thyroid cancer diagnosis with clinicopathological information and undergoing thyroidectomy; informed about the aim of the study; and volunteered to participate. The exclusion criteria were as follows: language barriers, severe cognitive impairment, mental diseases, far geographical distance, presence of other primary tumors, refusal to participate, and incapable of independently filling out the questionnaires.

\section{Evaluation Tools of QoL}

Face-to-face semi-structured interviews were offered either to coincide with a future hospital appointment or at the patient's home at a time that is convenient for them. QoL was assessed using the European Organization for Research and Treatment of Cancer Quality of Life Questionnaire Core 30 (EORTC QLQ-C30), which was originally proposed by Aaronson et al. ${ }^{10}$ The QLQ-C30 includes 30 items and measures 5 functional scales (i.e., physical, role, emotional, cognitive, and social functioning), global health status, financial difficulties, and 8 symptom scales (i.e., fatigue, nausea and vomiting, pain, dyspnea, insomnia, appetite loss, constipation, and diarrhea). ${ }^{11}$ A summary score was calculated from 13 scales (excluding global QoL and financial difficulties), with the symptom scales being reversed (100-symptom scale) to obtain a uniform direction of all scales, ${ }^{12,13}$ as follows: QLQ-C30 summary score $=$ (physical functioning + role functioning + social functioning + emotional functioning + cognitive functioning $+[100-$ fatigue $]+[100-$ pain $]+[100-$ nausea/vomiting $]+[100-$ dyspnea $]+[100$ - insomnia $]+[100-$ appetite loss $]+[100-$ constipation $]$ $+[100-$ diarrhea $]) / 13$.

\section{Predictive Factors Affecting QoL}

To identify factors at diagnosis that were predictive of QoL measured with EORTC QLQ-C30 at 3 months of follow-up, we investigated the effects of the following factors: age, gender, education, marital status, area of residence, and annual mean income. We also collected tumor characteristics, including histology (papillary, follicular, medullary, and undifferentiated), clinical stage, presence of metastasis, surgery type and radiotherapy. The extent of surgery was categorized as total thyroidectomy (total, subtotal, and near total) and lobectomy (partial lobectomy, lobectomy, and/or isthmusectomy). In addition, neurological deficits induced by recurrent nerve or superior laryngeal injury were collected.

\section{Sample Size}

The final model tested consisted of 13 dimensions, ${ }^{12}$ which resulted in an initial estimate of 260 individuals. However, we added a loss rate of $20 \%$, thereby increasing the minimum sample size to 286 individuals.

\section{Statistical Analyses}

Statistical analyses were performed using SPSS version 13.0 (SPSS Inc., Chicago, IL). Multivariate regression analyses were used to assess the associations of demographic and tumor characteristics with decreased QoL. A two-tailed $P<$ 0.05 was considered statistically significant.

\section{Results}

Among the 298 patients that were recently diagnosed with thyroid cancer after thyroidectomy, 5 patients refused to participate, 2 patients emigrated to other cities, 2 patients had mental disease, 3 patients could not independently fill out the questionnaires, and 286 patients were ultimately involved in this study. 
Table I Demographic and Tumor Characteristics of 286 Participants (n, \%)

\begin{tabular}{|c|c|c|c|}
\hline Demographic Characteristics & $(n, \%)$ & Tumor Characteristics & $(n, \%)$ \\
\hline Gender & & Histology & \\
\hline Male & $60(21.0 \%)$ & Papillary & $258(90.2 \%)$ \\
\hline Female & $226(79.0 \%)$ & Follicular & $24(8.4 \%)$ \\
\hline Age (year) & & Medullary & $4(1.4 \%)$ \\
\hline$\leq 60$ & $238(83.2 \%)$ & Clinical stage $(\mathrm{AJCC})$ & \\
\hline$>60$ & $48(16.8 \%)$ & I & $237(82.8 \%)$ \\
\hline Education & & II & $42(14.7 \%)$ \\
\hline Low (<12 years) & $239(83.6 \%)$ & III & $6(2.1 \%)$ \\
\hline High ( $\geq 12$ years) & $47(16.4 \%)$ & IV & I (0.4\%) \\
\hline Marital status & & Presence of metastasis & \\
\hline Married & $232(82.9 \%)$ & Yes & I $(0.4 \%)$ \\
\hline Unmarried/divorced & 49 (17.1\%) & No & 285 (99.6\%) \\
\hline Area of residence & & Surgery type & \\
\hline City & $87(30.4 \%)$ & Lobectomy & $194(67.8 \%)$ \\
\hline Rural or regional & 199 (69.6\%) & Total thyroidectomy & $92(32.2 \%)$ \\
\hline Annual mean income & & Radiotherapy & \\
\hline Low & $76(26.6 \%)$ & Yes & $19(6.6 \%)$ \\
\hline Middle & 155 (54.2\%) & No & $267(93.4 \%)$ \\
\hline \multirow[t]{3}{*}{ High } & 55 (19.2\%) & Neurological deficits & \\
\hline & & Yes & II (3.8\%) \\
\hline & & No & 275 (96.2\%) \\
\hline
\end{tabular}

Abbreviation: AJCC8, The 8th Edition of the American Joint Committee on Cancer.

The general information of demographic and tumor characteristics is shown in Table 1. Overall, the majority of the participants was female (79.0\%), aged $\leq 60$ years old (83.2\%), had low educational attainment (83.6\%), married $(82.9 \%)$, lived in rural or regional areas $(69.6 \%)$, and had middle mean income (54.2\%). Approximately $90.2 \%$ of patients had papillary cancer, $82.8 \%$ were clinical stage I, $0.4 \%$ had metastasis, $67.8 \%$ had undergone lobectomy, and $6.6 \%$ were undergoing radiotherapy. Of the patients, $3.8 \%$ had neurological deficits induced by recurrent nerve or superior laryngeal injury.

Multivariate regression analysis confirmed that clinical stage $(P<0.001)$, surgery type $(P<0.001)$, histology $(P<$ $0.001)$, neurological deficits $(P<0.001)$, and marital status $(P<0.001)$ were independent risk factors for decreased QoL 3 months after thyroidectomy (Table 2). Further analysis (Table 3) showed that clinical stage I, lobectomy, papillary, non-neurological deficits, and marital status were related to the QoL score.

\section{Discussion}

The concept of QoL is relatively new and has acquired growing importance in recent decades. Particular attention should be given to the QoL of patients, especially in the presence of risk factors impairing QoL. Although differentiated thyroid cancer is perceived as a "good cancer," cancer-related decreased QoL is still common for disease-free thyroid cancer survivors. ${ }^{14-19}$ The results of our study indicated decreased QoL in thyroid cancer survivors and that marital status, histology, clinical stage, and surgery type were independent risk factors for decreased QoL 3 months after thyroidectomy.

The reasons for decreased QoL remain largely unexplained, but several studies reported the possible reasons. Some authors have attributed decreased QoL to cancerrelated fatigue, which is a symptom that is frequently experienced by survivors regardless of tumor type or its treatment and not likely to be relieved by rest. ${ }^{20,21}$ Another possible explanation for decreased QoL is because replacement therapy with levothyroxine cannot normalize T4 and $\mathrm{T} 3$ concentrations in all tissues, ${ }^{22-24}$ which might play a role in persisting symptoms and decreased QoL among hypothyroid cancer patients. Emotional and psychological concerns are also largely unmet in thyroid cancer survivors. $^{25-27}$

A previous observational cross-sectional study showed that the factors influencing QoL are TNM stage, radioiodine therapy and dose, and presence of metastases. ${ }^{28} \mathrm{By}$ contrast, radiotherapy and presence of metastasis were not independent risk factors for decreased QoL at 3 months 
Table 2 Logistic Regression Analyses of Factors Associated with Decreased QoL

\begin{tabular}{|l|l|l|l|l|l|}
\hline & B Coefficient & Standard Error & P value & Beta & 95\% Confidence Interval for B \\
\hline Clinical stage & -10.569 & 0.729 & $<0.001$ & -0.555 & $-12.003--9.135$ \\
Surgery type & -4.179 & 0.688 & $<0.001$ & -0.217 & $-5.533--2.824$ \\
Histology & -6.340 & 0.888 & $<0.001$ & -0.252 & $-8.089--4.591$ \\
Neurological deficits & -8.472 & 1.802 & $<0.001$ & -0.181 & $-12.019--4.925$ \\
Marital status & -3.417 & 0.893 & $<0.001$ & -0.143 & $-5.176--1.659$ \\
\hline
\end{tabular}

Abbreviation: QoL, Quality of life.

Table 3 QoL at 3 Months After Thyroidectomy on the Basis of the Risk Factors

\begin{tabular}{|c|l|l|}
\hline & QoL Score & P \\
\hline Clinical stage (AJCC8) & $70.60(7.73)$ & $<0.00$ I \\
II & $54.62(12.3 \mathrm{I})$ & \\
III and IV & $38.12(5.64)$ & \\
\hline $\begin{array}{l}\text { Surgery type } \\
\text { Lobectomy }\end{array}$ & $70.60(6.92)$ & $<0.00$ I \\
Total thyroidectomy & $66.16(15.55)$ & \\
\hline $\begin{array}{l}\text { Histology } \\
\text { Papillary }\end{array}$ & $70.4 \mathrm{I}(7.04)$ & $<0.00$ I \\
Follicular and Medullary & $55.41(13.84)$ & \\
\hline $\begin{array}{l}\text { Neurological deficits } \\
\text { Yes }\end{array}$ & $45.77(6.75)$ & $<0.001$ \\
No & $70.09(8.16)$ & \\
\hline $\begin{array}{l}\text { Marital status } \\
\text { Married } \\
\text { Unmarried/divorced }\end{array}$ & $70.60(5.75)$ & $<0.001$ \\
\hline
\end{tabular}

Note: Continuous variables are presented as median (interquartile range) due to abnormal distribution.

Abbreviations: QoL, Quality of life; AJCC8, The 8th Edition of the American Joint Committee on Cancer.

after thyroidectomy in our study. We speculated that the discrepancy might be related to low incidence, with $0.4 \%$ of patients with metastasis and $6.6 \%$ undergoing radiotherapy. Consistent with previous report, marital status was also associated with low QoL scores, indicating that family support is considerably important to thyroid cancer survivors. ${ }^{29}$ Patients do not know what kind of symptoms they may be facing and are often left alone with their diagnosis and fears. Family, particularly the patient's spouse, is central to all aspects of social support, including emotional, instrumental, and informational support.

The introduction of advances in diagnostic methods combined with increased medical surveillance and access to health care services led to the overdiagnosis of thyroid cancer, ${ }^{30,31}$ which may have never caused symptoms or harm if undetected. ${ }^{32,33}$ In addition, the majority of patients who were diagnosed with thyroid cancer underwent total thyroidectomy. In a previous study, Nickel et al reported that overdiagnosis leads to physical and psychological burdens, which are more prevalent among patients who have total thyroidectomy than those who have hemithyroidectomy. ${ }^{30}$ Moreover, Conzo et $\mathrm{al}^{34}$ reported that hemithyroidectomy may avoid adverse effects, such as recurrent laryngeal nerve paralysis and permanent hypoparathyroidism, and lead to low mean hospitalization stays and costs. Considering low-risk follicular neoplasm solitary lesions, hemithyroidectomy remains the safest standard. ${ }^{34}$ In case of multiglandular disease or highly malignant tumor, which might be associated with a high risk of cancer, total thyroidectomy is recommended. ${ }^{35}$

This study had several potential limitations. First, the duration might not have been sufficiently long. Studies with longer follow-up durations are needed to determine the long-term effects of factors on the QoL in these patients. Second, endocrine function includes T4 therapy, and the levels of T4 suppression need to be evaluated. Third, the data were collected from a single center, and the sample was relatively small. Fourth, the cohort of study participants might not entirely reflect the Chinese population; that is, our sample lacks the diversity of race/ethnicity.

In conclusion, the results of our study indicated that marital status, histology, clinical stage, and surgery type were independent risk factors for decreased QoL 3 months after thyroidectomy. Future studies are needed to investigate these factors in depth, possibly allowing health resources to be allocated to support patients with thyroid cancer.

\section{Abbreviation}

QoL, Quality of life.

\section{Disclosure}

The authors report that no funding was received for this study and that they have no conflicts of interest in this work. 


\section{References}

1. Verburg FA, Mader U, Tanase K, et al. Life expectancy is reduced in differentiated thyroid cancer patients $\geq 45$ years old with extensive local tumor invasion, lateral lymph node, or distant metastases at diagnosis and normal in all other DTC patients. $J$ Clin Endocrinol Metab. 2013;98:172-180. doi:10.1210/jc.2012-2458

2. Maier TM, Schober O, Gerss J, et al. Differentiated thyroid cancer patients more than 60 years old paradoxically show an increased life expectancy. J Nucl Med. 2015;56:190-195. doi:10.2967/jnumed. 114.150284

3. Osoba D. Health-related quality of life and cancer clinical trials. Ther Adv Med Oncol. 2011;3:57-71. doi:10.1177/1758834010395342

4. Perros P, Boelaert K, Colley S, et al. Guidelines for the management of thyroid cancer. Clin Endocrinol (Oxf). 2014;81(Suppl 1):1-122.

5. Botella-Carretero JI, Galan JM, Caballero C, Sancho J, EscobarMorreale HF. Quality of life and psychometric functionality in patients with differentiated thyroid carcinoma. Endocr Relat Cancer. 2003;10:601-610. doi:10.1677/erc.0.0100601

6. Giusti M, Sibilla F, Cappi C, et al. A case-controlled study on the quality of life in a cohort of patients with history of differentiated thyroid carcinoma. J Endocrinol Invest. 2005;28:599-608. doi:10. 1007/BF03347258

7. Tagay S, Herpertz S, Langkafel M, et al. Health-related quality of life, depression and anxiety in thyroid cancer patients. Qual Life Res. 2006;15:695-703. doi:10.1007/s11136-005-3689-7

8. Schultz PN, Stava C, Vassilopoulou-Sellin R. Health profiles and quality of life of 518 survivors of thyroid cancer. Head Neck. 2003;25:349-356. doi:10.1002/hed.10217

9. Applewhite MK, James BC, Kaplan SP, et al. Quality of life in thyroid cancer is similar to that of other cancers with worse survival. World J Surg. 2016;40:551-561. doi:10.1007/s00268-015$3300-5$

10. Aaronson NK, Ahmedzai S, Bergman B, et al. The European Organization for Research and Treatment of Cancer QLQ-C30: a quality-of-life instrument for use in international clinical trials in oncology. J Natl Cancer Inst. 1993;85:365-376. doi:10.1093/jnci/ 85.5.365

11. Fayers P, Bottomley A. Quality of life research within the EORTC-the EORTC QLQ-C30. European Organisation for Research and Treatment of Cancer. Eur J Cancer. 2002;38(Suppl 4):S125-S133. doi:10.1016/S0959-8049(01)00448-8

12. Ratjen I, Schafmayer C, Enderle J, et al. Health-related quality of life in long-term survivors of colorectal cancer and its association with all-cause mortality: a German cohort study. BMC Cancer. 2018;18:1156. doi:10.1186/s12885-018-5075-1

13. Giesinger JM, Kieffer JM, Fayers PM, et al. Replication and validation of higher order models demonstrated that a summary score for the EORTC QLQ-C30 is robust. $J$ Clin Epidemiol. 2016;69:79-88. doi:10.1016/j.jclinepi.2015.08.007

14. Goswami S, Mongelli M, Peipert BJ, Helenowski I, Yount SE, Sturgeon C. Benchmarking health-related quality of life in thyroid cancer versus other cancers and United States normative data. Surgery. 2018;164:986-992. doi:10.1016/j.surg.2018.06.042

15. Gamper EM, Wintner LM, Rodrigues M, et al. Persistent quality of life impairments in differentiated thyroid cancer patients: results from a monitoring programme. Eur $J$ Nucl Med Mol Imaging. 2015;42:1179-1188. doi:10.1007/s00259-015-3022-9

16. Singer S, Lincke T, Gamper E, et al. Quality of life in patients with thyroid cancer compared with the general population. Thyroid 2012;22:117-124. doi:10.1089/thy.2011.0139

17. Hedman C, Djarv T, Strang P, Lundgren CI. Determinants of long-term quality of life in patients with differentiated thyroid carcinoma - a population-based cohort study in Sweden. Acta Oncol. 2016;55:365-369. doi:10.3109/0284186X.2015.1102965
18. Saravanan P, Visser TJ, Dayan CM. Psychological well-being correlates with free thyroxine but not free 3,5,3'-triiodothyronine levels in patients on thyroid hormone replacement. J Clin Endocrinol Metab. 2006;91:3389-3393. doi:10.1210/jc.2006-0414

19. Wekking EM, Appelhof BC, Fliers E, et al. Cognitive functioning and well-being in euthyroid patients on thyroxine replacement therapy for primary hypothyroidism. Eur $J$ Endocrinol. 2005;15 3:747-753. doi:10.1530/eje.1.02025

20. Husson O, Nieuwlaat WA, Oranje WA, Haak HR, van de Poll-franse LV, Mols F. Fatigue among short- and long-term thyroid cancer survivors: results from the population-based PROFILES registry. Thyroid. 2013;23:1247-1255. doi:10.1089/thy.2013.0015

21. Bower JE. Prevalence and causes of fatigue after cancer treatment: the next generation of research. J Clin Oncol. 2005;23:8280-8282. doi:10.1200/JCO.2005.08.008

22. Escobar-Morreale HF, Del Rey FE, Obregon MJ, de Escobar GM. Only the combined treatment with thyroxine and triiodothyronine ensures euthyroidism in all tissues of the thyroidectomized rat. Endocrinology. 1996;137:2490-2502. doi:10.1210/endo.137.6.864 1203

23. Ladenson PW. Psychological wellbeing in patients. Clin Endocrinol (Oxf). 2002;57:575-576. doi:10.1046/j.1365-2265.2002.01682.x

24. Weetman AP. Whose thyroid hormone replacement is it anyway? Clin Endocrinol (Oxf). 2006;64:231-233. doi:10.1111/cen.2006.64. issue-3

25. Huang JK, Ma L, Song WH, Lu BY, Huang YB, Dong HM. Quality of life and cosmetic result of single-port access endoscopic thyroidectomy via axillary approach in patients with papillary thyroid carcinoma. Onco Targets Ther. 2016;9:4053-4059. doi:10.2147/ OTT.S99980

26. Husson O, Zebrack BJ, Block R, et al. Health-related quality of life in adolescent and young adult patients with cancer: a longitudinal study. J Clin Oncol. 2017;35:652-659. doi:10. 1200/JCO.2016.69.7946

27. Goldfarb M, Casillas J. Health-related quality of life in adolescent and young adult patients with cancer: a longitudinal study. $J$ Cancer Surviv. 2014;8:394-401. doi:10.1007/s11764-014-0345-7

28. Haraj NE, Bouri H, El Aziz S, Nani S, Habti N, Chadli A. Evaluation of the quality of life in patients followed for differentiated cancer of the thyroid. Ann Endocrinol (Paris). 2019;80:26-31. doi:10.1016/j. ando.2018.01.003

29. Wang T, Jiang M, Ren Y, et al. Health-related quality of life of community thyroid cancer survivors in Hangzhou, China. Thyroid. 2018;28:1013-1023. doi:10.1089/thy.2017.0213

30. Nickel B, Tan T, Cvejic E, et al. Health-related quality of life after diagnosis and treatment of differentiated thyroid cancer and association with type of surgical treatment. JAMA Otolaryngol Head Neck Surg. 2019;145:231-238. doi:10.1001/jamaoto.2018.3870

31. Dal Maso L, Panato C, Franceschi S, et al. The impact of overdiagnosis on thyroid cancer epidemic in Italy, 1998-2012. Eur $J$ Cancer. 2018;94:6-15. doi:10.1016/j.ejca.2018.01.083

32. Brito JP, Hay ID. Thyroid cancer: overdiagnosis of papillary carcinoma - who benefits? Nat Rev Endocrinol. 2017;13:131-132. doi:10.1038/nrendo.2016.224

33. Rahman ST, McLeod DSA, Pandeya N, et al. Understanding pathways to the diagnosis of thyroid cancer: are there ways we can reduce over-diagnosis? Thyroid. 2019;29:341-348. doi:10.1089/thy.2018.0 570

34. Conzo G, Calo PG, Gambardella C, et al. Controversies in the surgical management of thyroid follicular neoplasms. Retrospective analysis of 721 patients. Int J Surg. 2014;12:S29-S34. doi:10.1016/j. ijsu.2014.05.013

35. Conzo G, Polistena A, Calo PG, et al. Efficacy of combined treatment for anaplastic thyroid carcinoma: results of a multinstitutional retrospective analysis. Int $J$ Surg. 2014;12:S178-S182. doi:10.1016/j. ijsu.2014.05.015 


\section{Publish your work in this journal}

Cancer Management and Research is an international, peer-reviewed open access journal focusing on cancer research and the optimal use of preventative and integrated treatment interventions to achieve improved outcomes, enhanced survival and quality of life for the cancer patient.

The manuscript management system is completely online and includes a very quick and fair peer-review system, which is all easy to use. Visit http://www.dovepress.com/testimonials.php to read real quotes from published authors.

Submit your manuscript here: https://www.dovepress.com/cancer-management-and-research-journa 